\title{
Tribology of o/w Emulsions Under Mouth-like Conditions: Determinants of Friction
}

\author{
Diane M. Dresselhuis • H. Jan Klok • \\ Martien A. Cohen Stuart • Renko J. de Vries • \\ George A. van Aken • Els H. A. de Hoog
}

Received: 8 July 2007 / Accepted: 14 August 2007 /Published online: 11 September 2007

(C) Springer Science + Business Media, LLC 2007

\begin{abstract}
Fat-perception is thought to be related to a complex interplay between fat-associated flavor release and mouth-feel. Friction sensed between the tongue and the palate seems to play a prominent role: in previous work, we have shown that emulsions that are more sensitive toward coalescence give rise to a lowering of the orally perceived and experimentally measured friction and, probably as a consequence, to an enhanced fat-perception. In this paper, we study in detail the factors determining friction of protein-stabilized emulsions using a novel mouth-mimicking tribometer and model surfaces consisting of PDMS modified in various ways (hydrophobicity, deformability, roughness). We show that unlike in many technological applications where lubrication is essentially hydrodynamic, for physiologically relevant loads, the modified PDMS is boundary and/or mixed lubricated, which is like in-mouth lubrication. We find that an increased sensitivity of the emulsions toward coalescence results in a lower friction, confirming previous results obtained with pig's tongue. Surface-induced coalescence (or spreading of emulsion droplets) seems to be very important in this, surface
\end{abstract}

D. M. Dresselhuis · H. J. Klok · G. A. van Aken •

E. H. A. de Hoog $(\square)$

Top Institute Food and Nutrition, formerly known as WCFS,

P.O. Box 557, 6700 AN Wageningen, The Netherlands

e-mail: els.de.hoog@NIZO.nl

D. M. Dresselhuis - M. A. C. Stuart • R. J. de Vries Laboratory of Physical Chemistry and Colloid Science, Wageningen University and Research Centre,

P.O. Box 8038, 6700 EK Wageningen, The Netherlands

H. J. Klok · G. A. van Aken • E. H. A. de Hoog

NIZO food research B.V.,

P.O. Box 20, 6710 BA Ede, The Netherlands hydrophobicity being the dominant trigger. Viscosity of the dispersed phase does not have such a strong influence on both the measured friction and the oral perceived friction. We do find a strong influence of the presence of bulk proteins and saliva on friction. Finally, hardly any dependence of measured friction on fat content of the emulsion was observed, indicating that only a small amount of fat is needed to alter the friction.

Keywords Tribology · Adhesion · Coalescence · Sensory · Oral mucosa $\cdot$ Saliva

\section{Introduction}

Designing food emulsions that contain less fat but nevertheless give a full-fat sensation is of great commercial and public interest. Fat perception is considered to be related to both fat-associated flavor release and mouth-feel. Mouth-feel of food is often linked to rheological in-mouth behavior. However, various authors suggested that rheological behavior alone cannot explain mouth-feel but that a relation between in-mouth friction and fat-related mouthfeel can. ${ }^{1-5}$ Recently, we demonstrated an inverse relation between perception of fat and in-mouth friction sensed between tongue and palate. ${ }^{6}$ In addition, we showed that food oil-in-water $(\mathrm{o} / \mathrm{w})$ emulsions, which are sensitive toward coalescence, give rise to a lower orally perceived and measured friction and, probably as a consequence, have an enhanced fat perception. Although knowledge on the relation between friction and fat perception is still rather limited, it is clear that understanding the tribology of food emulsions under mouth-like conditions would be an important step toward understanding fat perception. However, at present, even a basic understanding of emulsion 
lubrication in general, ${ }^{7}$ and more specific, under mouth-like conditions is lacking. ${ }^{8}$

In contrast, friction, lubrication, and wear (or in short, tribology) have been extensively studied, for example, in the context of metal processing and other technologies. In tribology, three regimes of lubrication are typically distinguished, which are often identified by analyzing the shape of the so-called Stribeck curve [friction coefficient plotted against the sliding speed (or film thickness), illustrated in Fig. 1]. For most technological applications, the focus lies on how to minimize wear and optimize lubrication of the surfaces to reduce energy consumption. Therefore, attention is usually restricted to the hydrodynamic lubrication regime. In this regime, the opposing surfaces are completely separated upon sliding due to build up of a hydrodynamic pressure as a function of speed. This means that the ability to form a hydrodynamic film depends mainly on the viscosity of the lubricant, and surface characteristics are of minor importance.

On the other hand, the tongue has a rough surface due to the presence of papillae (height several hundreds of micrometers), ${ }^{9}$ which allow food handling for mastication purposes. Combined with the low speed of sliding and low contact pressures, it is clear that surface characteristics are crucially important for in-mouth lubrication, ${ }^{10}$ and that in-mouth lubrication is not in the hydrodynamic regime, but rather in the so-called boundary regime (where friction depends on the characteristics of the surfaces including the thin adsorbed boundary layer) or in the mixed regime, which forms the transition between the boundary and the hydrodynamic regime.

To understand how lubrication by food oil-in-water (o/w) emulsions can influence in-mouth friction and thus fat perception, we recently developed a mouth-mimicking tribometer, the optical tribological configuration (OTC). ${ }^{9}$ In contrast to the circular movement employed in traditional tribometers, in this tribometer, two surfaces slide over one another in a relative parallel movement. The parallel sliding

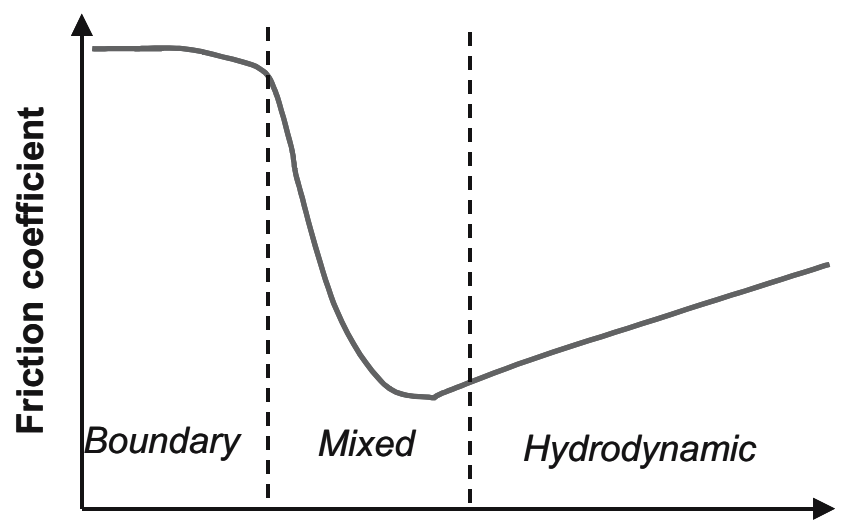

log sliding speed

Fig. 1. Stribeck curve with the three lubrication regimes movement has the advantage of being more similar to the inmouth situation of the tongue moving parallel to the palate than the circular rolling movements. Disadvantage of the parallel movement is that the ability to measure at very high speed is limited. Furthermore, the OTC allows the surfaces to move over a distance comparable to the tongue-palate situation. Furthermore, low loads of tenths of Newtons can be applied resulting in a contact pressure comparable to the in-mouth situation. At these low loads, wear phenomena are found to be negligible. Another feature of this tribometer is that we are not restricted to synthetic surfaces but can also use biological materials. For example, we have recently used the OTC with pig's tongue to mimic in-mouth lubrication., While there are clear reasons for studying tribology with real biological surfaces such as pig's tongue, there are clear disadvantages too: limited availability, variability between the tongue samples and especially the inability to alter the surface characteristics to test hypotheses and dependencies.

For these reasons, in this study, we use modified PolyDiMethylSiloxane (PDMS) to complement our studies using pig's tongue. The use of PDMS allows us to systematically alter a single surface characteristic such as the roughness, deformability, and hydrophobicity, without changing the others. Velocities reached in the OTC are similar to typical in-mouth velocities of food as was estimated from data on shear rates in the mouth. ${ }^{10}$ We exclusively use rough surfaces since the aim is to avoid the less relevant hydrodynamic regime of lubrication and instead focus on the boundary and/or mixed regime. Furthermore, rough surfaces give rise to complex flow behavior between the asperities, much like in the mouth. ${ }^{9}$ The tongue surface is not only rough, it also is notably hydrophobic, and highly deformable. ${ }^{9}$ Therefore, using our PDMS model surfaces, we vary not only roughness, but also hydrophobicity and deformability. Presumably, these factors will influence the formation of lubricating layers by emulsion components, which can influence friction, for example by altering adhesion between the surfaces.

Friction is not only determined by surface characteristics, but of course also by the lubricating fluid itself. In our previous studies, we have found a clear influence of the emulsions' sensitivity toward coalescence. This dependence will also be addressed in this study, now using the controlled PDMS surfaces. Furthermore, since it has been shown that the oil viscosity has a pronounced effect when droplets are not stabilized by a surfactant, we will address the influence of oil viscosity on friction and relate this to the sensorially perceived friction of the emulsions. ${ }^{11}$

Finally, for in-mouth lubrication, it is impossible to ignore the role of saliva. ${ }^{12-14}$ Most likely, saliva proteins (e.g., the mucin glyco-proteins) adhere to surfaces and influence friction in the boundary and mixed regime by changing adhesion between the surfaces. When considering 
protein-stabilized emulsions, the same considerations hold for the proteins in the aqueous phase. Therefore, we included a study on both the role of saliva and of bulkphase proteins.

\section{Materials and methods}

\section{Emulsion preparation}

The o/w emulsions containing $40 \mathrm{wt} \%$ oil were prepared according to the procedure described in Dresselhuis et al. ${ }^{6}$ Vanilla, sucrose, and salt were only added to emulsions that were sensorially tested. The emulsions were stabilized by either $1 \mathrm{wt} \%$ Whey Protein Isolate (WPI; BiPro, Davisco, USA) or $0.3 \mathrm{wt} \%$ WPI. Sunflower oil (SF; fully winterized sunflower oil, $\eta=60 \mathrm{mPa}$.s, gift by Cargill Amsterdam, The Netherlands) was used as the oil phase. The emulsions were diluted with the continuous phase to a $20,10,5$, and $1 \mathrm{wt} \%$ SF oil emulsion. The $1 \mathrm{wt} \%$ WPI stabilized emulsions were previously shown to be stable against coalescence under shear in the tribometer and in the mouth, while the $0.3 \mathrm{wt} \%$ WPI stabilized emulsion was shown to be unstable. ${ }^{6}$ Furthermore, emulsions stabilized by $1 \mathrm{wt} \%$ WPI were formulated with MCT oil (Miglyol $812 \mathrm{~N}$, Condea Chemie, Witten, Germany, $\eta=30 \mathrm{mPa} . \mathrm{s}$ ), olive oil (Olivae oleum virginale Fagron, Nieuwerkerk a/d Ijssel, The Netherlands, $\eta=81 \mathrm{mPa} . \mathrm{s})$ and Castor oil (Ricini oleum virginale, Fagron, Nieuwekerk a/d Ijssel, The Netherlands, $\eta=980 \mathrm{mPa} . \mathrm{s}$ ).

The average droplet size of the emulsions was $1.1 \mu \mathrm{m}$, $D[3,2]$, and $2.4 \mu \mathrm{m} D[4,3]$. The viscosity of the emulsions varied between $4.9 \mathrm{mPa}$.s (at $90 \mathrm{~s}^{-1}$ ) for $40 \mathrm{wt} \%$ oil emulsions to $2.1 \mathrm{mPa} . \mathrm{s}$ for $20 \mathrm{wt} \%, 1.4 \mathrm{mPa}$.s for $10 \mathrm{wt} \%$, $1.3 \mathrm{mPa} . \mathrm{s}$ for $5 \mathrm{wt} \%$ and $1.1 \mathrm{mPa} . \mathrm{s}$ for $1 \mathrm{wt} \%$ oil emulsions.

\section{Tribopairs}

A Poly-DiMethylSiloxane (PDMS) pin was manufactured according to the method described in Dresselhuis et al. and Lee et al. ${ }^{9,15}$ A commercial silicone elastomer kit (SYLGARD 184 DOW Corning, Midland, USA) containing a base and a cross linker was used. The cross linker was mixed with the base in a ratio 1:10 for "hard" pins $(0.64 \mathrm{mPa})$ and in a 1:20 ratio for "soft" pins $(0.16 \mathrm{mPa})$. The elastomer was cured in 96-well plates, which were sandblasted at two different pressures and served as moulds. The resulting pins had an average asperity height of around $4.5 \mu \mathrm{m}$ (roughness high, $\mathrm{RH}$ ) and $2 \mu \mathrm{m}$ (roughness low, RL). The radius of the spherical tip is $3 \mathrm{~mm}$. The water contact angle against air for the "hard" pins was $108^{\circ}$ and for the "soft" pins $90^{\circ}$. The pins were hydrophilized following the method of Lee et al. by oxygen-plasma-treatment for $2 \mathrm{~min}$ in a plasma-cleaner (Harrick PDC-32 G, Anadis instruments, Malden, The Netherlands). ${ }^{15}$ Oxidation of the surface altered the chemical characteristics to such an extent that it became hydrophilic. Note that the minor alterations in the chemical composition of the surface due to oxidation might also give rise to minor changes in other surface properties. The water contact angle on these oxidized PDMS surfaces was less than $5^{\circ}$. The pin was slid against a microscope glass coverslip $\left(R_{\mathrm{a}}=2 \mathrm{~nm},{ }^{9}\right.$ water contact angle $\left.65^{\circ}\right)$.

\section{Tribological study}

Tribology measurements were performed with the OTC, which is able to measure forces down to $8 \mathrm{mN}$. Roughly the same method was used as described in Dresselhuis et al. ${ }^{9}$ In short, an amount of $150 \mu \mathrm{l}$ emulsion was sheared in the OTC between PDMS/glass under a load $\left(F_{\mathrm{z}}\right)$ of $0.5 \mathrm{~N}$. During one experiment, the lower glass plate oscillated ten cycles over a distance of $16 \mathrm{~mm}$ against the upper PDMS pin. Simultaneously, the friction force $\left(F_{\mathrm{x}}\right)$ was measured, and the average friction force was calculated over the span of the movement where the speed of shearing was constant. The sliding speed varied from $0.01 \mathrm{~m} / \mathrm{s}$ until $0.08 \mathrm{~m} / \mathrm{s}$. A speed of $0.01 \mathrm{~m} / \mathrm{s}$ was chosen as the lower limit since a lower speed implies an increase in duration of the experiment resulting in dehydration of the sample.

Each experiment was carried out three times using new PDMS pins and fresh emulsions for every experiment. The PDMS pins were placed into the OTC measuring probe in such a way that the pins were spherical-shaped.

\section{Saliva}

To study the influence of saliva, the PDMS surfaces were coated with unstimulated saliva by covering the surface with an excess of saliva during 2 min. Unstimulated saliva was used since this contains the highest concentration of salivary proteins. It was found by Silletti et al. to give saliva-induced flocculation of emulsion droplets. ${ }^{16}$ Saliva was donated by five subjects (following the protocol of Silletti et al.) who refrained from eating for $2 \mathrm{~h}$ before donation. ${ }^{16}$ The subjects thoroughly rinsed their mouth before donating. The saliva was kept on ice during donation and then centrifuged to remove cells. Saliva was frozen in liquid nitrogen, stored at $-80^{\circ} \mathrm{C}$ and used within 6 weeks after donation.

\section{Sensory study}

The emulsions were sensorially evaluated following the same procedure as described earlier by a sensory trained panel according to the principles of quantitative descriptive 
analysis. ${ }^{6,17}$ In short, a panel of eight female panelists generated in separate sessions descriptive attributes of which 38 were used to profile the four different emulsions. ${ }^{6}$ The panelists were seated in climate-controlled sensory booths and judged the set of emulsions in a semimonadically assessment procedure in triplicate on visual analog scales. The acquisition was done by computer using FIZZ software (Biosystemes 2006, v2.20 A 2006, Couternon, France). The emulsions were evaluated on 4 odor $(\mathrm{O}), 10$ taste $(\mathrm{T}), 9$ mouth-feel $(\mathrm{M})$, 4 after-taste (AT) and 11 after-feel (AF) attributes.

\section{Results}

Before discussing the data on lubrication by protein-stabilized $\mathrm{o} / \mathrm{w}$ emulsions, we first consider lubrication by oil and water separately, for hydrophobic and hydrophilic PDMS, and for PDMS surfaces differing in roughness. All figures presented in this section have error bars. In cases where these are invisible, they are smaller than the symbol size.

\section{PDMS lubrication}

Oil wets hydrophobic surfaces much better than hydrophilic surfaces, hence oil may be expected to be a better lubricant for hydrophobic than for hydrophilic surfaces. Indeed, Fig. 2 shows that low viscosity MCT oil lubricates hydrophobic PDMS much better than it lubricates hydrophilic PDMS. Increasing the viscosity of the oil (SF, Castor) further reduces the measured friction on hydropho- bic PDMS. Note however, that this also decreases the difference with lubrication of hydrophilic PDMS.

As explained in the introduction, in the hydrodynamic and, to lesser extent, in the mixed regime, friction is mainly determined by the viscosity of the lubricant, rather than the surface properties (Fig. 1). For all oils, even for the highly viscous Castor oil, we observe a gradual decrease in the friction, as function of speed. Characteristic for the hydrodynamic regime is an increase in friction as function of speed (see Fig. 1). No increase in friction is observed in Fig. 2 indicating that for the rough PDMS surfaces used here we have boundary and/or mixed lubrication (see Fig. 1). The fact that for the most viscous oil (Castor) we find very little difference between lubrication of hydrophilic and hydrophobic PDMS may indicate that for this oil we do indeed approach the hydrodynamic regime. On the other hand, for the least viscous oil (MCT), there is a clear surface effect and hence, in this case we are in the boundary/mixed regime over the speed range tested here.

Besides surface hydrophobicity and viscosity of the lubricant, surface roughness is an important factor in lubrication. Indeed, comparing smooth PDMS with the rough PDMS used here we see a strong influence of roughness on lubrication. ${ }^{9}$ Figure 3 shows a clear difference in friction coefficient between hydrophobic surfaces with a low surface roughness (PDMS-RL) and high surface roughness (PDMS-RH) when water is the lubricant, but not when sunflower oil is the lubricant. Water is a better lubricant for PDMS surfaces with high surface roughness,

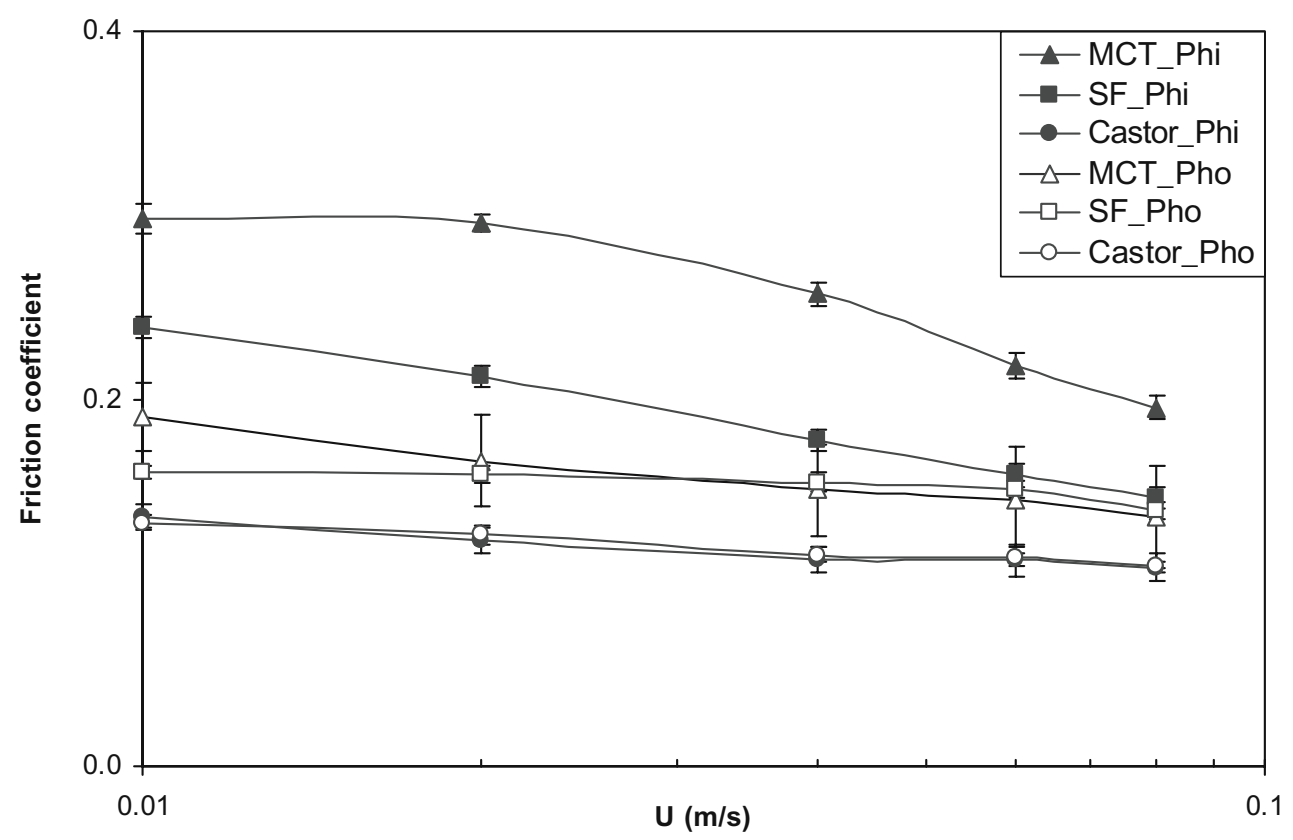

Fig. 2. Friction coefficient as a function of speed $(U)$ with oil varying in viscosity sheared between hydrophobic (open symbols) and hydrophilic (filled symbols) hard PDMS with roughness low $(R L)$; MCT oil 


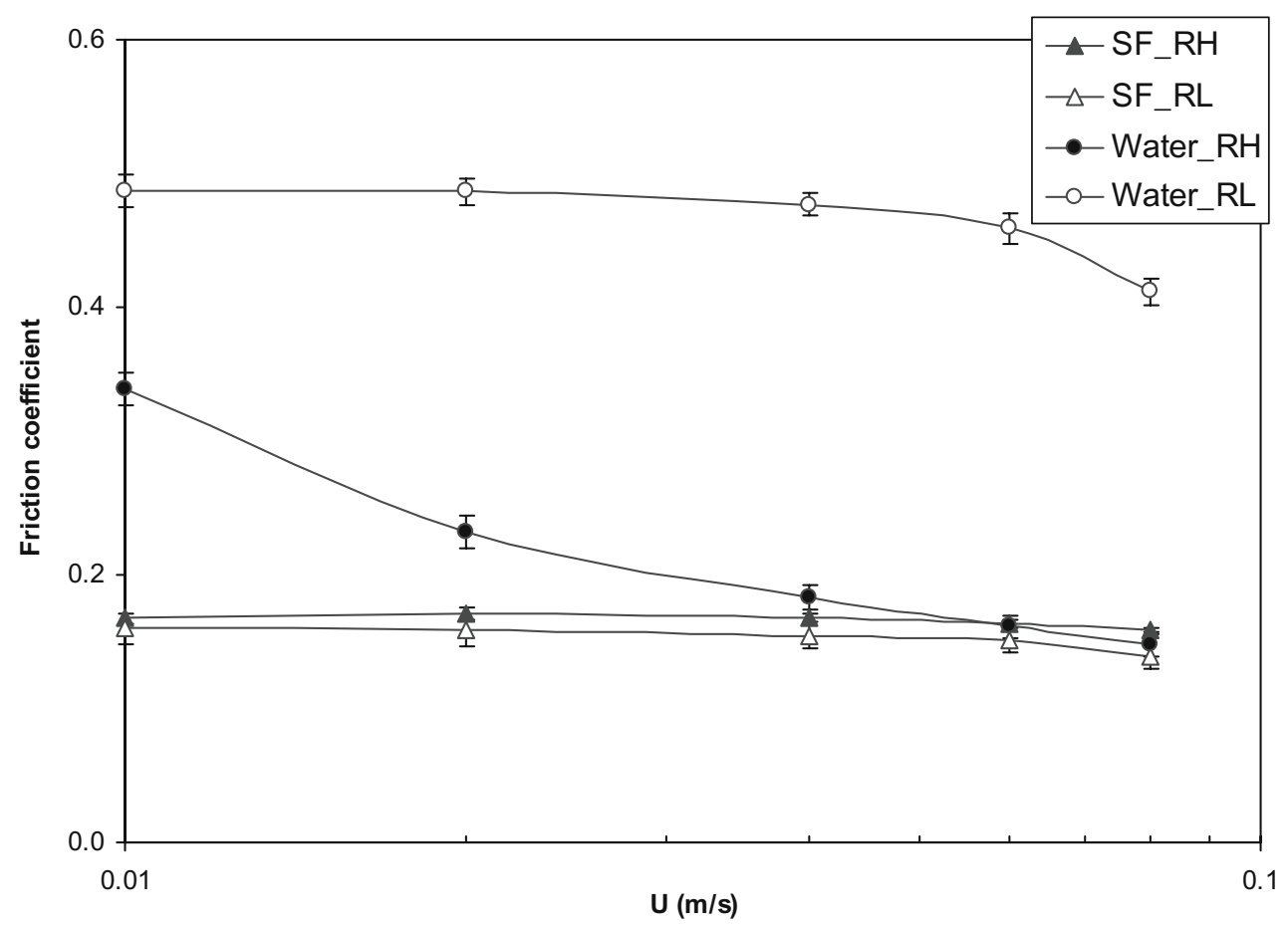

Fig. 3. Friction coefficient as a function of speed $(U)$ with hard PDMS (hydrophobic) varying in roughness high (RH; filled symbols) and low (RL; open symbols) with the lubricants sunflower oil _ـ and water

than for surfaces with low surface roughness. On the other hand, when sunflower oil is the lubricant, roughness does not seem to influence friction very strongly. Apparently, for this case, the higher viscosity, together with the ability to wet the hydrophobic surface, implies that we are further away from the boundary regime where surface properties are dominant. However, the (slight) decrease in friction as function of speed indicates that also in this case the lubrication of the surfaces is boundary/mixed.

For none of the measured combinations do we see strongly increasing friction coefficients as function of sliding speed. Increasing friction as function of speed is characteristic for the hydrodynamic regime. Although we cannot access a wide enough range of loads and speeds to cover the entire Stribeck curve, we can conclude that under the conditions that we use, we are certainly not in the hydrodynamic regime. As surface properties not always dominate lubrication and viscosity of the lubricants sometimes does play a role, we are not always in the boundary regime either. In short, under the conditions we apply in the OTC and using modified PDMS surfaces, the regime of lubrication is boundary and/or mixed, but certainly not hydrodynamic. Next we consider lubrication of PDMS by food emulsions.

Surface properties

We investigated (using PDMS) the influence of surface hydrophobicity and deformability on emulsion lubrication for emulsions of fixed composition. First, however, we briefly compare emulsion lubrication with lubrication by the oil and water separately. One might expect that, as long as the emulsion droplets do not stick to the PDMS and remain stable, emulsion lubrication should be similar to water lubrication considering the fact that the viscosity of the continuous phase is almost equal to water. However, Fig. 4 clearly shows that even the unstable emulsion is always a worse lubricant than either oil or water. In "Salivary and bulk proteins", we will return to this finding when discussing the role of emulsions stabilizers (proteins) and the role of saliva. Despite the observation that the emulsion does not resemble either water or oil in terms of friction, it lubricates hydrophobic surfaces better than hydrophilic ones. This could be explained by the fact that oil tends to spread on hydrophobic surfaces, which happens when emulsion droplets coalesce on the surface. On hydrophilic surfaces, this tendency is much less strong, even in the presence of proteins.

As for the deformability, Figure 5 shows that the difference between soft and hard PDMS lubrication lies mainly in the shape of the (partial) Stribeck curve. For soft PDMS, the friction is almost constant as function of the speeds, and only starts to decrease at the highest sliding speed. On the other hand, for hard PDMS, the friction is gradually decreasing with the sliding speed, indicative for mixed lubrication. In other words, an increase in deformability of the surfaces leads to an extended boundary regime, since the adhesion between soft surfaces is higher than between hard surfaces. 


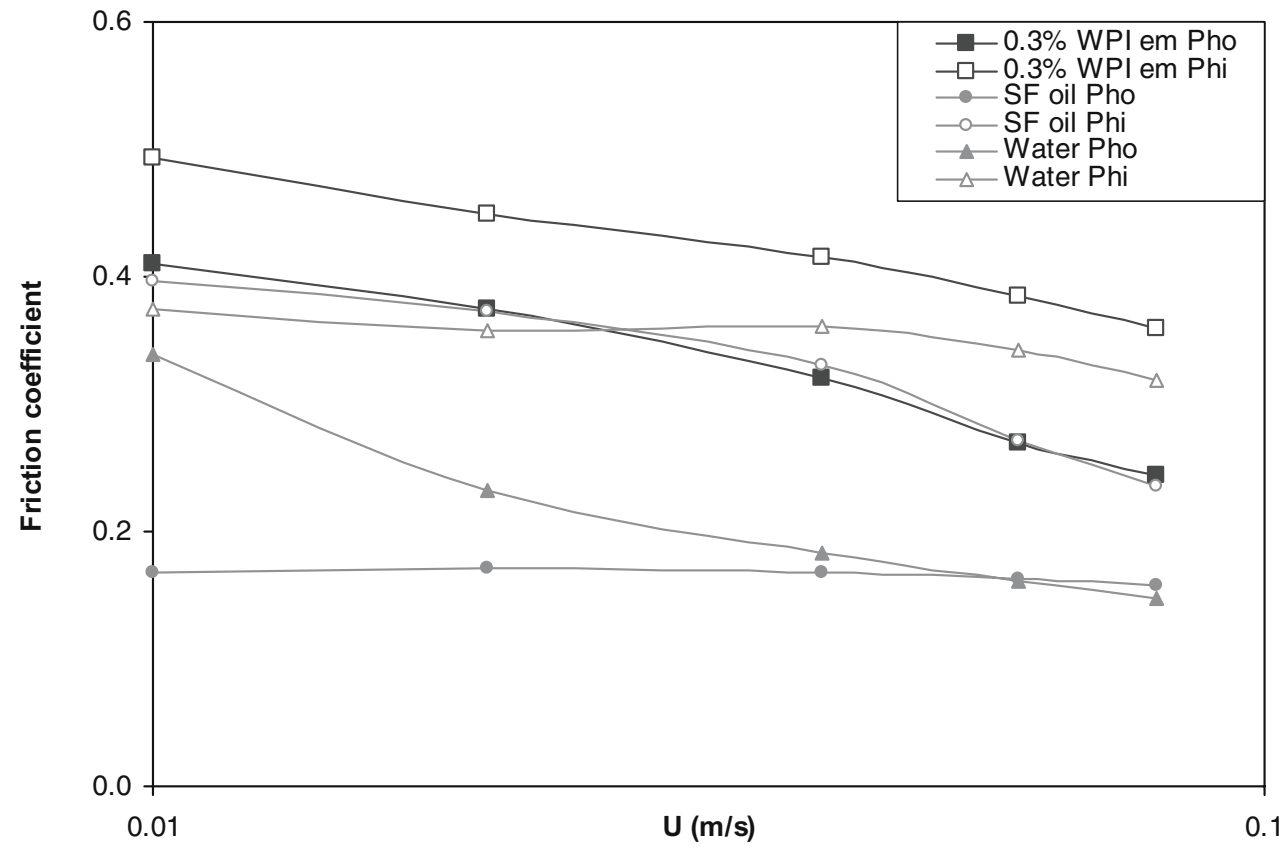

Fig. 4. Friction coefficient as function of speed $(U)$ of $0.3 \mathrm{wt} \%$ WPI $40 \mathrm{wt} \%$ SF emulsion — sheared between hydrophobic hard PDMS (filled symbol) and hydrophilic hard PDMS (open symbol) in comparison to SF oil — and water $\longrightarrow$. Roughness is $R H$

Emulsion characteristics

So far, we have only considered emulsions of a fixed composition and considered the influence of surface properties on friction. Next, we will also vary emulsion properties and see how these influence lubrication. Here, we study the dependence of friction on emulsion stability, fat content, viscosity of the dispersed phase using our model PDMS surfaces. In addition, the effect of viscosity of the dispersed phase on oral-perceived friction is determined. First, consider the role of emulsion (un)stability in lubrication. We expect that surface-induced coalescence, possibly facilitated by shear-induced coalescence (see insert Fig. 7), is capable of lowering the friction. By surfaceinduced coalescence, we here mean the process in which oil droplets, either stabilized or not, spread on a solid surface. More surface-induced coalescence will primarily occur on hydrophobic surfaces and with unstable emulsions. Indeed,
Fig. 5. Friction coefficient as a function of speed $(U)$ with PDMS (hydrophobic, RH) varying in deformability, hard PDMS (filled symbols), soft PDMS (open symbols), with an emulsion (0.3 wt $\%$ WPI, $40 \mathrm{wt}$ $\% \mathrm{SF}$ ) acting as a lubricant

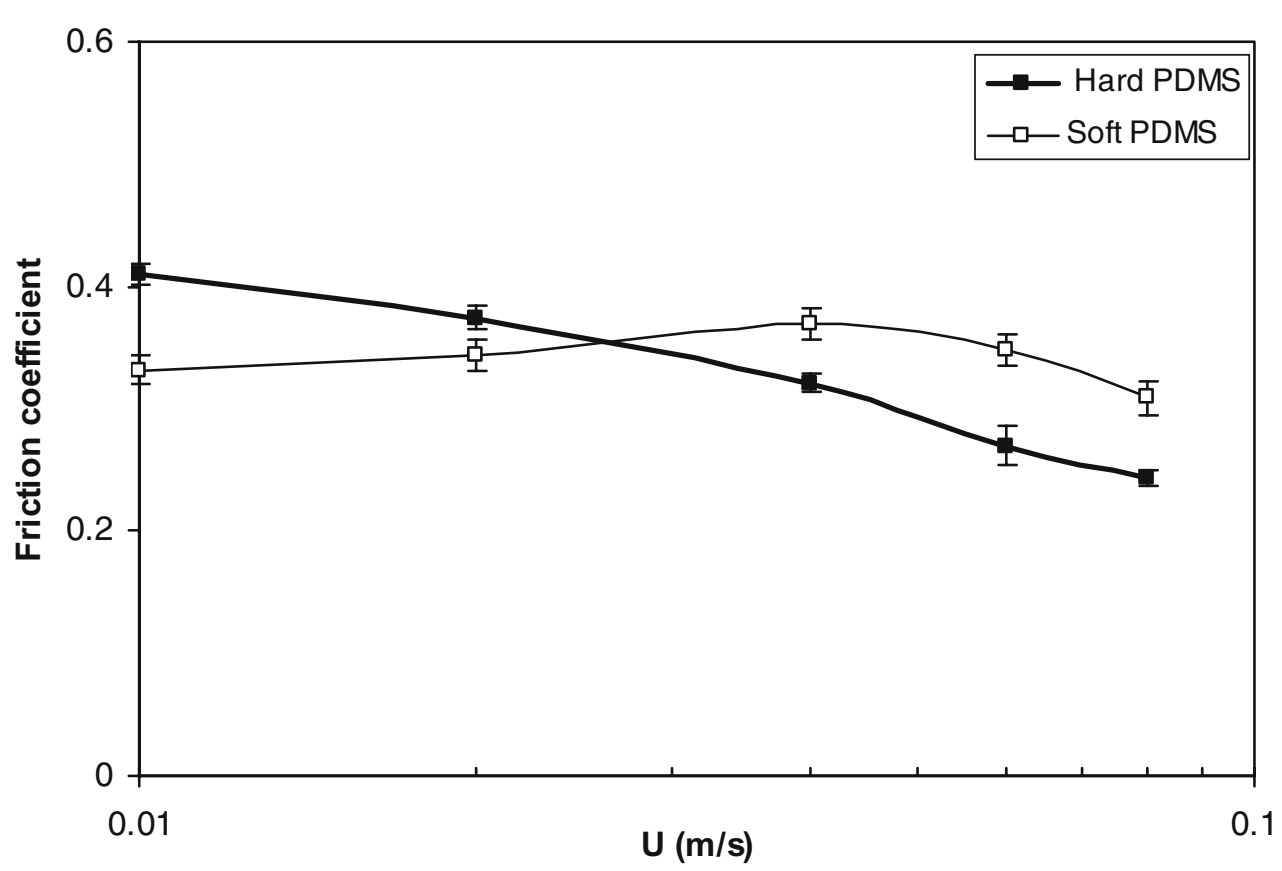


we see in Fig. 6 that the gradual decrease in friction as function of speed (typically for mixed lubrication) for the unstable ( $0.3 \%$ WPI emulsion) is steeper than for the more stable, 1\% WPI emulsion on hydrophobic PDMS. Hence, the unstable emulsion gives rise to a lower friction than the stable emulsion. Figure 6 also shows that protein solutions are worse lubricants than either an emulsion or water. The role of protein in lubrication will be discussed in detail in further sections. In brief, unstable emulsions are more effective in lowering of the friction than stable emulsions.

The question is, can this difference in emulsion stability be explained in terms of sensitivity to shear-induced coalescence, or is it mainly due to a stronger tendency to surface-induced coalescence? To determine whether the stable $1 \%$ WPI emulsion was sensitive to shear, we checked the influence of shear history on the friction, and sheared the stable emulsion in different ways: either using step-wise increases on a single emulsion that remained in the OTC, or by using fresh emulsion for each new speed. We expect that if shear-induced coalescence would occur at a certain speed, the presence of the enlarged droplets (which are more sensitive toward further coalescence; shear and/or surface-induced) would affect the Stribeck curve at the following higher speeds. As is evident in Fig. 7, there seems to be no effect whatsoever of shear history, indicating that hardly any shear-induced coalescence has occurred and that lowering of the friction with the speed was mainly due to entering deeper into the mixed regime. Thus, unstable emulsions indeed give rise to a lower friction than stable emulsions on hydrophobic PDMS. The distinction whether this difference is due to a difference in sensitivity to shear could not be made. The viscosities of both emulsions are very similar, so the differences that we observe must have their origin in properties of the lubricating layer, indicating that surface-induced coalescence is likely to play a prominent role.

\section{Fat content}

Reduction in friction by emulsions is expected to be mainly determined by the formation of an oil film, as a result of surface-induced coalescence. Therefore, we expect a critical amount of fat to be necessary to form oil patches, which significantly reduce the friction. Surface roughness probably affects how easily such layers are formed and, hence, was also taken into account as a variable.

Figure 8 shows that, except for the $0.3 \mathrm{wt} \%$ WPI $40 \mathrm{wt} \%$ $\mathrm{SF}$ emulsion, there is hardly any dependence on surface roughness at a sliding speed of $0.08 \mathrm{~mm} / \mathrm{s}$. Possibly, this is because of the relatively small difference in surface roughness (mean asperity height $2 \mu \mathrm{m}$ vs $4.5 \mu \mathrm{m}$ ). Indeed, we did find a substantial decrease in friction when comparing the $4.5 \mu \mathrm{m}$ PDMS surface roughness with a very smooth $(2 \mathrm{~nm})$ PDMS surface roughness (data not shown). ${ }^{9}$ The most remarkable effect is, however, that there is hardly any difference in friction between a $5-\mathrm{wt} \%$ and a $40-w t \%$ fat emulsion. Apparently, only a small amount of oil is needed to form a lubricating layer.

Next, we investigate whether there is a lower limit to the amount of fat needed to form a lubricating layer, by decreasing the fat content to even lower values. The effect of surface hydrophobicity and emulsion stability was also studied. Figure 9 shows that even an emulsion with a fat percentage of $1 \mathrm{wt} \%$ lowers the friction just as efficiently as
Fig. 6. Influence sensitivity to coalescence on friction; friction coefficient as function of speed $(U)$ with emulsions, $0.3 \mathrm{wt} \%$ WPI $40 \mathrm{wt} \% \mathrm{SF} \longrightarrow$ and $1 \mathrm{wt} \%$ WPI $40 \mathrm{wt} \% \mathrm{SF}-\square-$, and protein solutions, $0.3 \mathrm{wt} \%$ WPI solution $-\longrightarrow$ and $1 \mathrm{wt}$ $\%$ WPI solution - - sheared between hydrophobic hard PDMS, roughness is RH

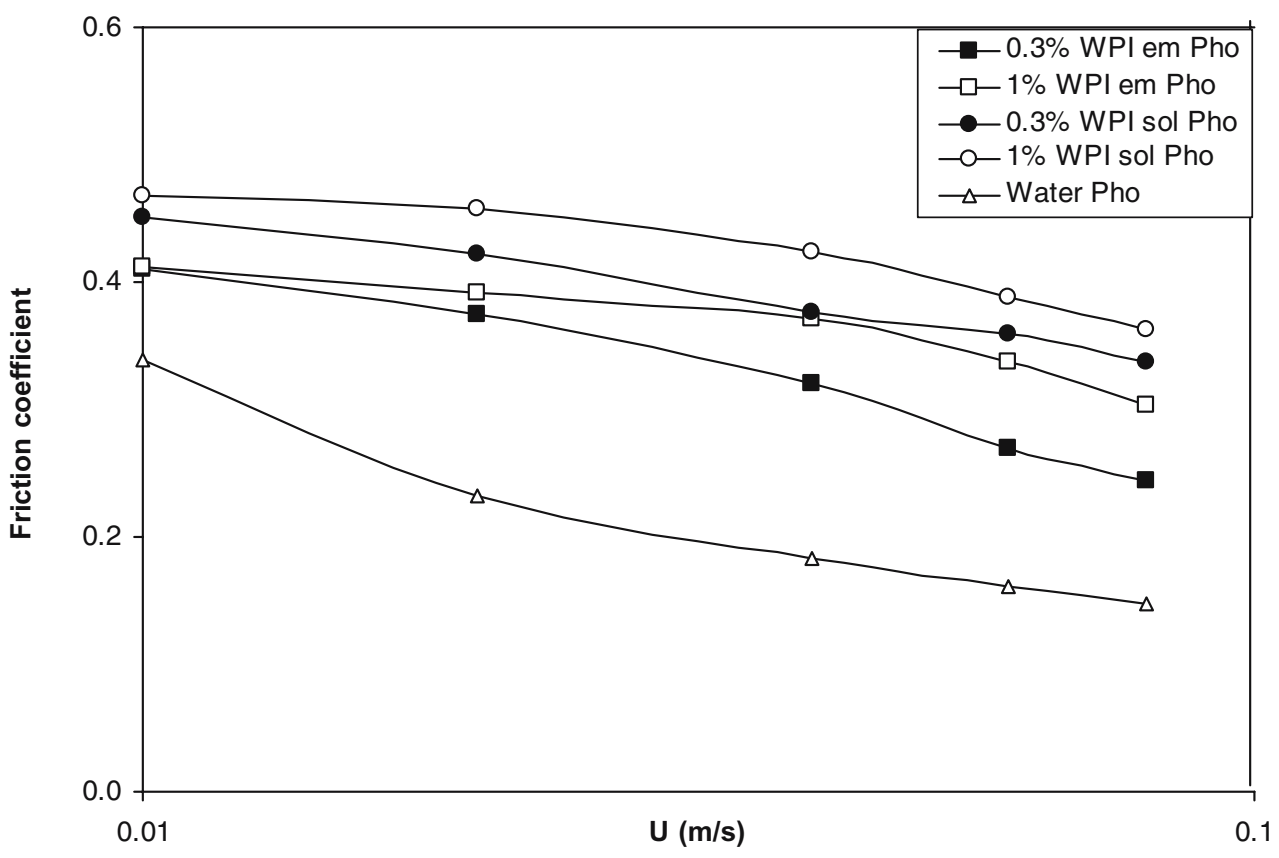




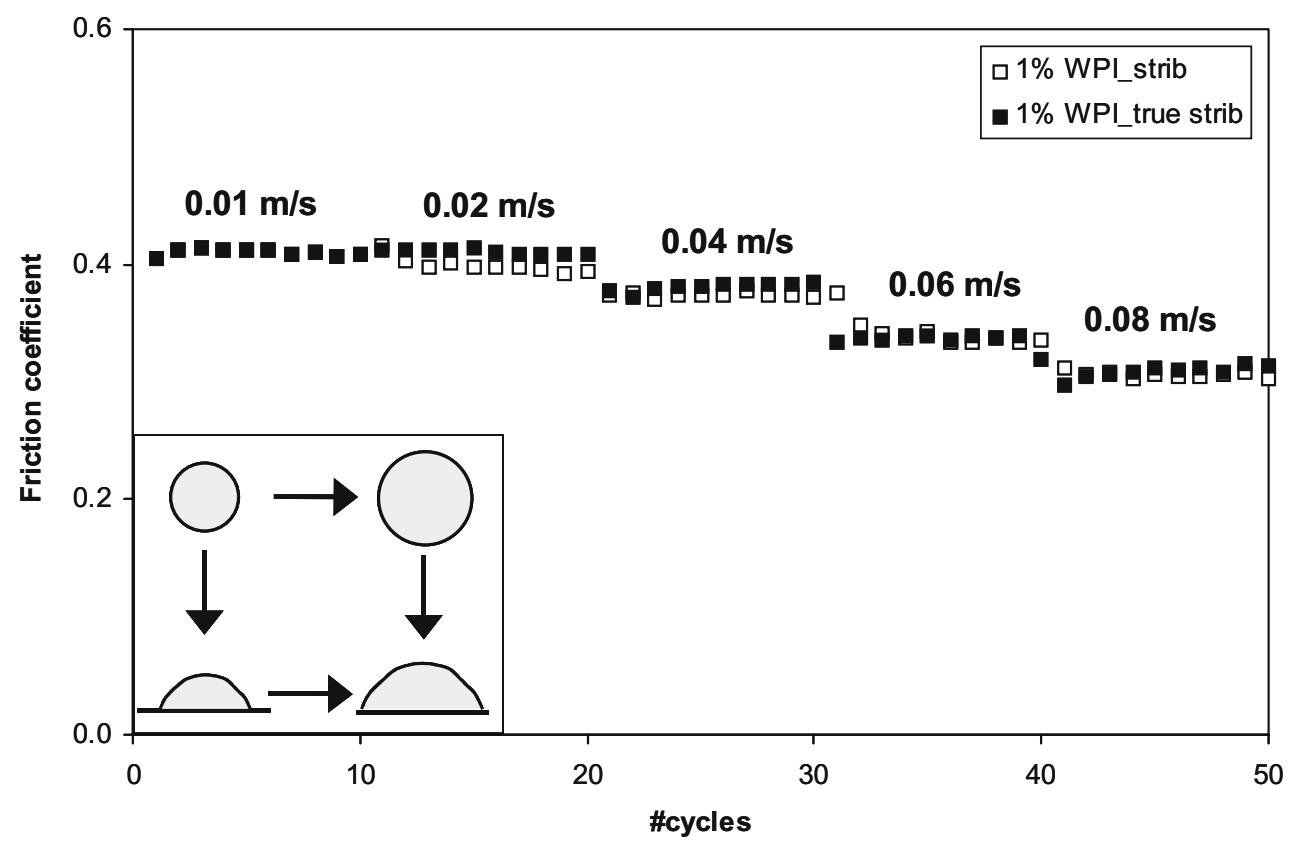

Fig. 7. Friction coefficient measured for every cycle at speeds varying from 0.01 until $0.08 \mathrm{~m} / \mathrm{s}$ between glass and hard hydrophobic PDMSRH with $1 \mathrm{wt} \%$ WPI $40 \mathrm{wt} \% \mathrm{SF}-\square-$ as a lubricant in comparison to

the friction coefficient measured for the different speeds separately, $1 \mathrm{wt}$ $\%$ WPI $40 \mathrm{wt} \% \mathrm{SF} \longrightarrow$ (true Stribeck curve). The insert shows how shear-induced coalescence can facilitate surface-induced coalescence

a $40 \mathrm{wt} \%$ emulsion, independently of surface hydrophobicity. As shear-induced coalescence depends on the oil content, this observation gives further evidence that the reduction in friction is mainly due to oil deposition as a result of surface-induced coalescence. Also note that the least stable emulsion, $0.3 \%$ WPI, lubricates a hydrophobic surface better than the stable, 1\% WPI, emulsion, again confirming earlier findings (Fig. 6) and strongly suggesting the importance of surface-induced coalescence. For a hydrophilic surface, the reverse is the case. The difference possibly lies both in the extent of surface-induced coalescence, and in a difference in protein adsorption for the two surfaces, to which we will return shortly.

\section{Viscosity of the oil}

We consider the influence of the viscosity of the dispersed phase on the friction of food emulsions under mouth-like

Fig. 8. Friction coefficient as function of fat percentage of two different emulsions $0.3 \mathrm{wt} \%$ WPI emulsion (black) and $1 \mathrm{wt}$ $\%$ WPI emulsions (grey) sheared between hydrophobic hard PDMS RH (filled) and RL (dashed) sheared $0.08 \mathrm{~m} / \mathrm{s}$

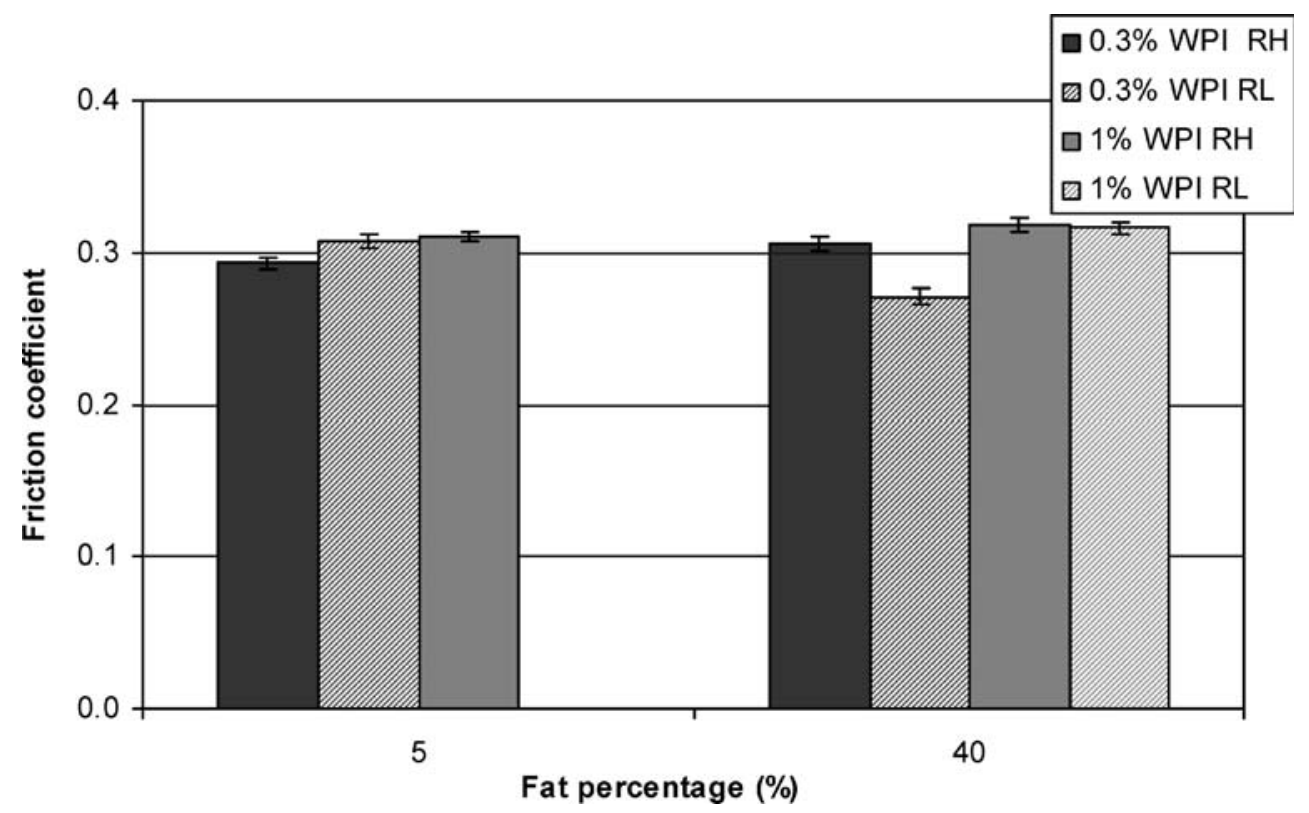




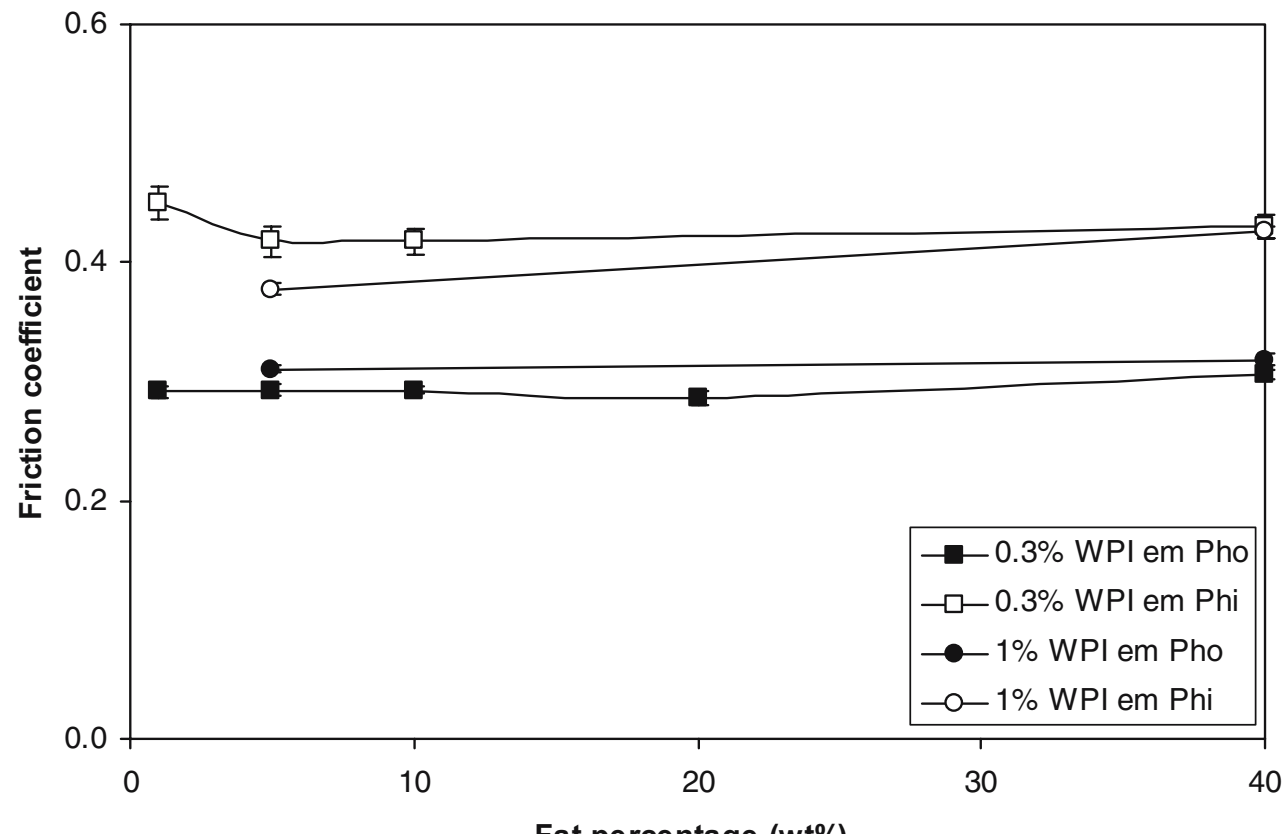

Fat percentage (wt\%)

Fig. 9. Friction coefficient as function of fat percentage of emulsions sheared at $0.08 \mathrm{~m} / \mathrm{s}: 0.3 \mathrm{wt} \% \mathrm{WPI} 40 \mathrm{wt} \% \mathrm{SF}-$ $40 \mathrm{wt} \% \mathrm{SF} \longrightarrow$ between hard hydrophobic PDMS (filled symbol) and hard hydrophilic PDMS (open symbol). Roughness is RH

conditions. Although the viscosities of the dispersed phases are highly different, the viscosities and droplet size distributions of the emulsions were nearly the same.

The results in Fig. 10 show that in all cases, the friction for emulsified oil is much higher than for nonemulsified oil. The expected decrease in emulsion friction with oil viscosity is not observed. Instead, the emulsion containing the highly viscous Castor oil gives a higher friction in the low speed regime but shows a sharp decrease in friction in the high-speed regime, indicating mixed lubrication of the surfaces. On the other hand, judging from the shape of the partial Stribeck curve, the emulsions with the less viscous oils are more in the boundary regime throughout the whole speed range covered. These stable $(1 \% \mathrm{WPI})$ emulsion

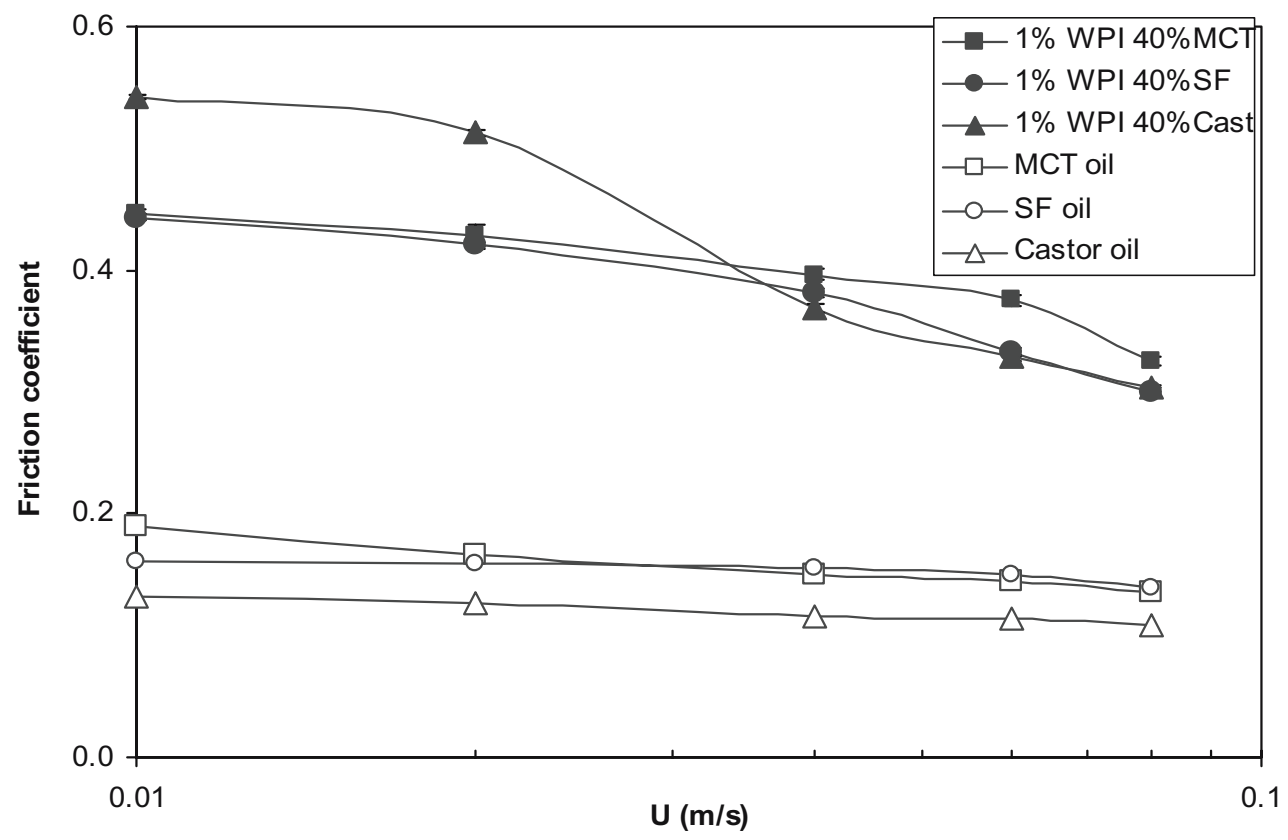

Fig. 10. Friction coefficient as function of speed with $1 \%$ WPI emulsified oils differing in viscosity (filled symbols)

- SF oil (medium viscosity), oil and nonemulsified oils (open symbols), sheared between glass and hydrophobic hard PDMS (RL) 
droplets are not expected to spread on the surface and, also due to their size, a difference in deformability (as a result of variation in oil viscosity) is not reflected in the friction data. In other words, viscosity of the dispersed phase hardly changes the character of emulsion lubrication for droplets around $1 \mu \mathrm{m}$.

To see whether the difference in oil type does have a sensorial effect, the emulsions with a similar composition as in the friction experiments were sensorially evaluated using a trained quantitative descriptive analyses (QDA) panel. Besides viscosity, also the amount of oil was varied. Figure 11 shows that the high viscous Castor oil emulsion receives the highest scores on fat-related attributes such as thickness, fattiness, slipperiness, but not on creaminess. On the other hand, we do not find the inverse relation between perceived oral friction (AFrough, AFdry, AFraw tongue) and viscosity of the oil phase as we expected. In contrast, we find a positive relation between oral friction and viscosity. However, overall the sensory results did not show a significant difference in perception as function of viscosity of the dispersed phase, indicating that we can only deduce trends. This absence of a clear viscosity effect is in agreement with the friction results (Fig. 9). Presumably, the morphology of the tongue and the speed of entrainment between tongue and palate is such that also here, no coalescence occurred with the stable emulsion, and thus, no lowering of the friction was perceived. In other words, due to the stability of the emulsions and the undeformability of the droplets no effect of viscosity on oral perceived friction has been found. Illustrative for the finding that emulsion stability is essential for lowering the friction are the following results on a low fat emulsion $(2 \%$ MCT). As expected, lowering of the fat percentage resulted in a dramatic decrease in perception of fat-related attributes. However, the low fat emulsion was also perceived as lowest in friction (Mdry, AFrough, AF raw tongue), which is in contrast with earlier findings that the emulsion with the lowest friction is also perceived as most fat. ${ }^{6}$ Apparently, when emulsions are stable, a $2 \%$ MCT oil emulsion is not very different from a $20 \% \mathrm{MCT}$ oil emulsion, in terms of perceived roughness, the $2 \% \mathrm{MCT}$ oil even being perceived as lower in friction than the $20 \%$ MCT oil. In other words, the stability of an emulsion seems to determine the mouthfeel perception of fat. This indicates that an emulsion can be perceived as 'fatty' due to, most likely, aroma release but will only be perceived as 'creamy' if an oil layer is formed on the oral tissue, thereby lowering the perceived friction.

\section{Salivary and bulk proteins}

An important aspect that needs to be considered in understanding food emulsion lubrication is the influence on friction of an important component of these emulsions: proteins. Comparing emulsified oil with nonemulsified oil (Figs. 4 and 10), or comparing protein solutions with emulsions and/or water (Fig. 6) on hydrophobic PDMS we found already several indications that protein adhesion can strongly increase the friction. On the other hand, we also found examples in which protein adherence presumably facilitates emulsions lubrication, like in the case of lubrication of hydrophilic PDMS (Fig. 9), a surface on which in absence of proteins oil droplets would not spread. Considering these previous indications and literature found on this subject (see "Introduction"), we investigated the
Fig. 11. The rated sensory intensity at the different attributes on emulsions varying in dispersed phase from low-viscosity oil MCT to high-viscosity Castor oil. Error bar indicates standard error. Olive oil has a viscosity comparable to sunflower oil. The sensory attributes on the left are fat-related and on the right friction-related. $M$, mouth-feel; $A F$, after-feel; $O$, odor/aroma; $A T$, after-taste and $T$, taste attributes

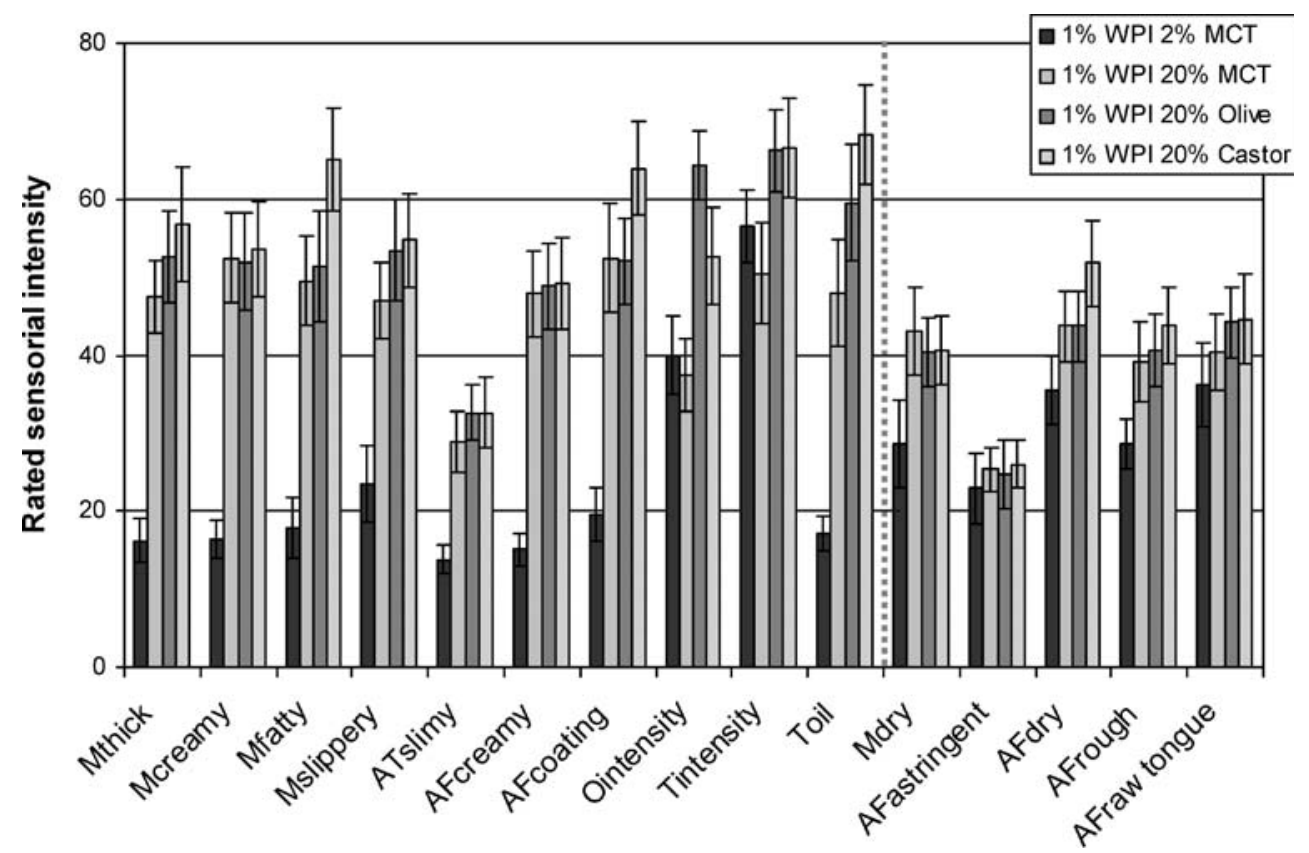


influence of protein content in the continuous phase (bulk proteins) on emulsion lubrication. We also consider the influence that salivary proteins can have on lubrication and on emulsion lubrication. The latter is of importance since mouth surfaces are naturally covered with salivary proteins and we ultimately aim at understanding in-mouth lubrication.

To determine what the influence is of bulk proteins on lubrication by an unstable $0.3 \mathrm{wt} \%$ WPI stabilized emulsion and a stable $1 \mathrm{wt} \%$ WPI stabilized emulsion, we measured friction coefficients as a function of estimated protein concentration in the continuous phase (assuming $2 \mathrm{mg} / \mathrm{m}^{2}$ surface load). ${ }^{18}$ First of all, Figure 12 shows that there is no linear relation between bulk protein concentration and measured friction over the protein concentration regime used. Secondly, Figure 12 reveals that the relation between friction coefficient and protein concentration is different for the different emulsions (stable vs unstable). This implies that unstable emulsions lubricate the surface better than the stable emulsion, independent of the bulk protein concentration. Furthermore, Figure 12 shows that protein solutions always give rise to a higher friction force than the $0.3 \%$ WPI stabilized emulsion indicating that the presence of fat or particles does have an effect on the friction. In short, the difference in measured friction between shearing a $0.3-w t \%$ stabilized emulsion and a $1-w t \%$ stabilized emulsion is the result of the combined effects of protein adherence and surface-induced coalescence, in which oil spreading due to surface-induced coalescence is the main effect.
In view of the in-mouth conditions relevant for the sensory perception of emulsions, we also investigated the influence of salivary proteins. The tongue is a hydrophobic surface, and since saliva is the natural lubricant covering the tongue, ${ }^{9}$ saliva is expected to lubricate the hydrophobic PDMS surface quite well. Surprisingly, the results in Fig. 13 show that saliva gives a much higher friction than both water and emulsion. This is remarkable since saliva largely consists of water, and furthermore, a low friction is expected with the main biological lubricant of the mouth, saliva, present in the tribological contact. Apparently, saliva components, such as the mucin glycoproteins, behave similar as bulk proteins (Fig. 12) regarding adherence and increasing the friction. When the glass and PDMS surfaces were coated with saliva and the emulsion was sheared between the coated surfaces, the friction is increased in comparison to the emulsion alone, and slightly lowered in comparison to saliva alone. In summary, adherence of proteins from either the emulsion, saliva, or both largely increases the friction.

\section{Discussion}

With the ultimate aim of understanding fat perception, in this work, we have studied lubrication by protein-stabilized emulsions under in-mouth conditions. To our knowledge, no study has been performed so far that addresses the regime of oral lubrication by food emulsions. Malone et al.

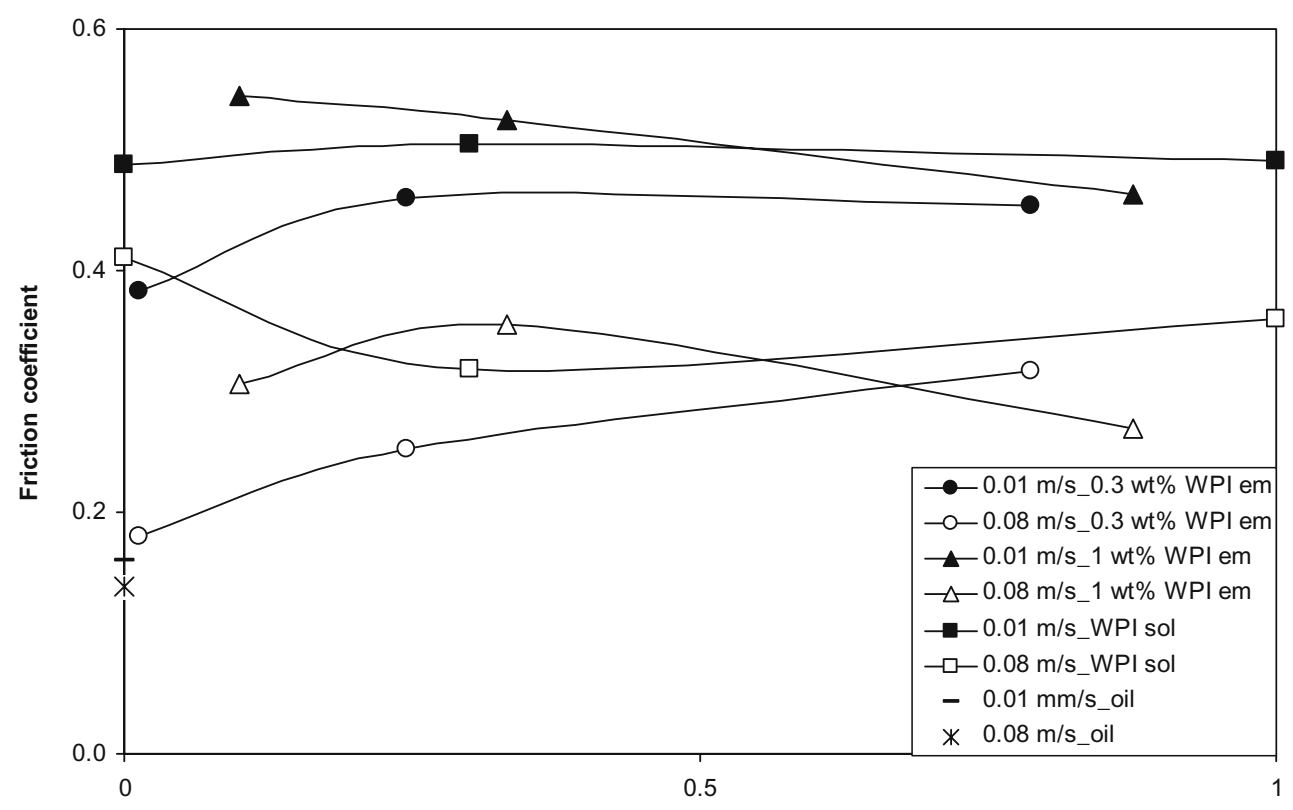

Amount of protein in continous phase (g prot/100 gram em)

Fig. 12. Friction coefficient as function of protein concentration in the continuous phase of two emulsions: $0.3 \mathrm{wt} \%$ WPI $5 \mathrm{wt} \% \mathrm{SF}$ and $1 \mathrm{wt} \%$ WPI $5 \mathrm{wt} \% \mathrm{SF}$ solutions - Oil as comparison (dash and asterisk) Closed symbols speed of shearing $0.01 \mathrm{~m} / \mathrm{s}$, open $0.08 \mathrm{~m} / \mathrm{s}$; sheared with hard hydrophobic PDMS-RL 
Fig. 13. Friction coefficient measured at $0.08 \mathrm{~m} / \mathrm{s}$ between glass and either uncoated or saliva-coated hydrophobic hard PDMS (RH) with emulsion ( $0.3 \mathrm{wt} \%$ WPI $10 \mathrm{wt} \% \mathrm{SF}$ ) as lubricant compared with SF oil, water, and saliva as lubricants

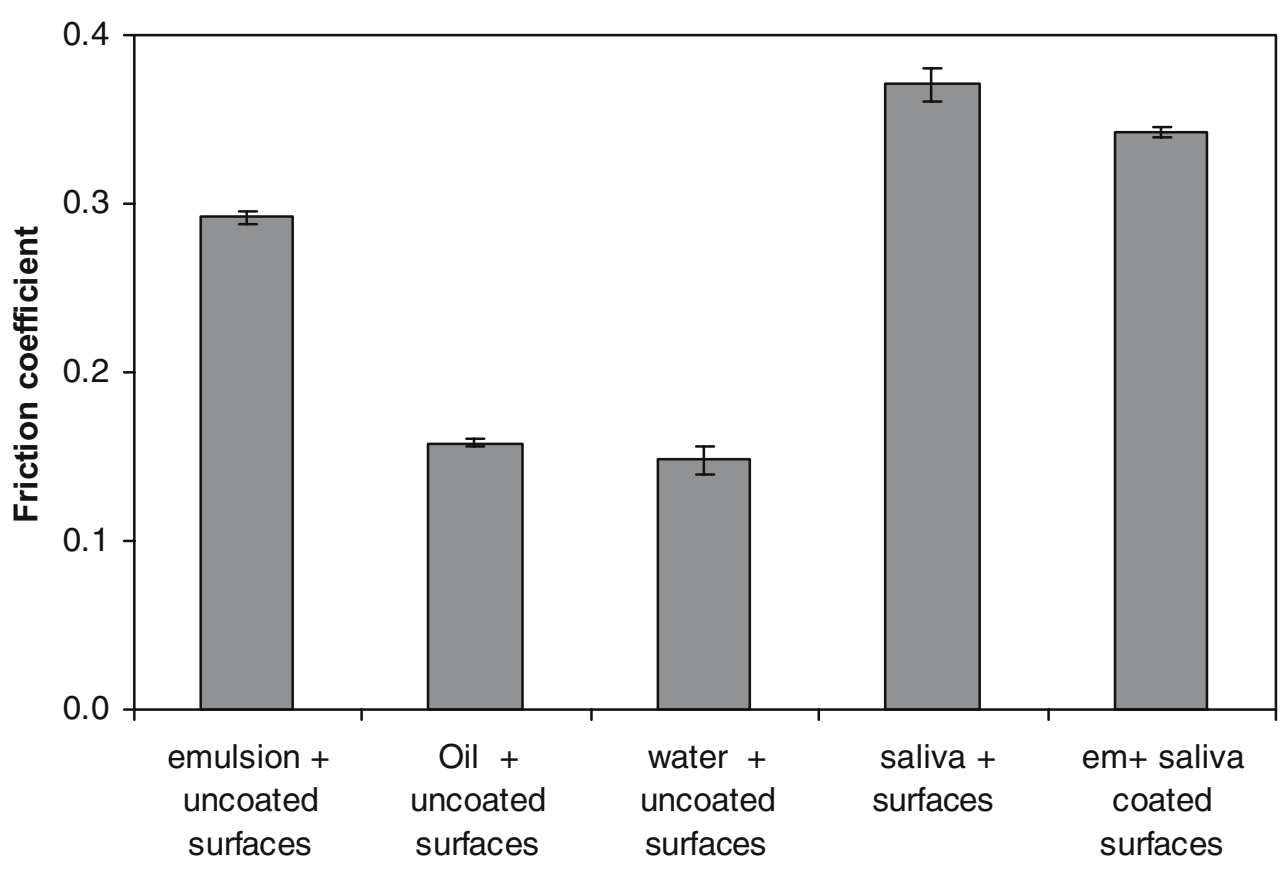

did find correlations between sensory perceived slipperiness and friction results in the mixed regime using biopolymer solutions as lubricant. ${ }^{4}$ However, different from Malone's, our set-up makes a parallel sliding movement instead of circular, and we use spherical rough surface on a flat smooth surface instead of very smooth ball (which rolls instead of slides) on a smooth surface and our applied load is lower. Moreover, we use protein-stabilized unthickened food emulsions as lubricant instead of surfactant stabilized thickened emulsions. Identifying the regime of lubrication is the essential first step in understanding oral lubrication. We argue that in-mouth lubrication of food emulsions is in the boundary/mixed regime, implying that viscosity of the nonthickened emulsion is often not the most important characteristic, but rather the ability of the emulsion to interact with the surface. We clearly show that under the mouth-like conditions applied in our tribometer (OTC) modified PDMS is not hydrodynamic but boundary and/or mixed lubricated using the separate Newtonian liquids oil and water as well as emulsions (Figs. 2 and 4) as lubricants. Note that due to the limited speed range the OTC covers, we cannot distinguish whether altering the surface and/or lubricant parameters result in a shift within the Stribeck curve or in a shift of the Stribeck curve.

While there is essentially no previous literature on how food emulsions lubricate the mouth, there are some relations with findings on hydrodynamic emulsion lubrication in the context of industrial processing of, e.g., metal. In these applications, boundary/mixed lubrication is usually avoided. On the other hand, the boundary/mixed regimes are often crucial in the field of bio-lubrication, e.g., in joint and prosthetic material lubrication. ${ }^{19-24}$ Below, we discuss some of the relevant papers from the areas of hydrodynamic emulsion lubrication and bio-lubrication, and relate them to the work presented here.

One of the questions we have tried to answer is how emulsions lubricate surfaces. In industrial processing of metal, o/w emulsions are widely used as lubricant in the hydrodynamic regime between hard contacts. However, the mechanism of lubrication by $\mathrm{o} / \mathrm{w}$ emulsions is still not yet fully understood. As a consequence, the design of lubricious emulsions is still quite empirical. ${ }^{7}$ In their study focussed at understanding emulsion lubrication, Cambiella et al. found that interaction between the surfaces and the oil droplets determines the mechanism of lubrication and that this interaction is primarily controlled by the emulsifier concentration, and thus also by the emulsion stability. ${ }^{7}$ Consistent with this, Dubey et al. reported an inverse relation between emulsion stability and lubrication in their experiments on cold rolling of steel. ${ }^{8}$ In earlier work, we also found that emulsions, which are more sensitive toward coalescence, are better lubricants. ${ }^{6}$ Indeed, the present work confirms the importance of emulsion stability for lubrication (Fig. 6). We also found more indications that surface-induced coalescence is an important mechanism in lowering the friction, as we argued before. ${ }^{6}$ In other words, friction is determined by oil covering the contact points and/or oil film formation due to oil release from the emulsion.

An important finding is that the friction for unstable emulsions is always well above the friction of nonemulsified oil. This points to additional sources of friction, most likely, layers of proteins in the lubrication contacts. This is an issue that also arises in the field of bio-lubrication, where it has 
been shown that proteins adhere to surfaces and influence friction in the boundary and mixed regime by changing adhesion between the surfaces. Sibarani et al. found that proteins adhere more at hydrophobic surfaces (such as PDMS) than at less-hydrophobic surfaces (such as Polyvinlychloride, PVC). ${ }^{25}$ In contrast to this, Heuberger et al. and Widmer et al. reported reduced protein adherence at hydrophobic surfaces in comparison to hydrophilic surfaces. ${ }^{19,24}$ Furthermore, they report that adherence of proteins, in general, increases boundary friction, and the largest increase in friction is found at hydrophobic surfaces. Karuppiah et al. also found an increase in boundary friction as function of protein concentration. ${ }^{21}$ However, they report, using the same surface as Widmer et al. ${ }^{24}$ a higher friction on hydrophilic UHMWPE (ultrahigh molecular weight polyethylene used in total joint replacements) surfaces instead of on hydrophobic UHMWPE. Our friction experiments confirm the observed higher friction as function of protein concentration (Fig. 12) on hydrophobic PDMS. In addition, Malone et al. found an increase in sensory perceived oral friction (astringency) as function of adhered amount of heat-treated milk on a mucin-coated surface, which implies that adherence of protein can have a sensory effect.

However, in-mouth lubrication by food emulsions is certainly not determined by protein-induced friction alone: we have clearly shown that the presence of oil lowers the friction. But how much oil is needed for this effect? The amount of oil necessary to lower the friction has been addressed De Hoog et al. ${ }^{26}$ They found that there was no effect of oil content in the regime $10-40 \mathrm{wt} \%$ oil. Furthermore, Malone et al. varied the fat content of their surfactant-stabilized emulsions. ${ }^{4}$ They did find an effect of fat in the mixed regime between $1-15 \mathrm{wt} \%$ and so did de Wijk and Prinz with their custards varying in fat content. ${ }^{5}$ However, Malone and Prinz used smooth rubber surfaces and thickened emulsions, whereas De Hoog used unthickened emulsions and rough oral surfaces. In the present work, we lowered the oil content further to $1 \mathrm{wt} \%$ and found that for both stable and unstable emulsion there is still no effect of oil content, which is for unthickened protein-stabilized emulsions, in agreement with De Hoog. ${ }^{26}$ In other words, only a very small amount of oil is sufficient for lowering the friction. Given the fact that there is an inverse relation between fat perception and friction, ${ }^{1-6}$ these findings contradict the sensory findings that fat content very clearly has an effect on fat perception and therefore on friction. ${ }^{4,27-29}$

Deformability of emulsion droplets is also expected to influence emulsion lubrication. Vicente et al. suggested in their work that at a high viscosity ratio between dispersed and continuous phase, the droplets become undeformable and are forced into the contact zone at high speeds, resulting in coalescence of the droplets. ${ }^{11}$ Note that their emulsion droplets are not stabilized by either surfactant or protein and larger and therefore more deformable than the droplets used here. Considering the work done earlier on the effect of coalescence on perception, this would indicate that high viscosity dispersed phases (viscous oil) lower the perceived oral friction and thus increase the perception of fat related attributes such as creaminess. ${ }^{6}$ Sensorial analyses indicate that the small undeformable droplets have hardly any influence on perception and the perceived friction is increased instead of decreased. There are some indications that there is a relation with viscosity of the dispersed phase and perception of fat-related attributes such as fatty, thick, but not with creamy. Most likely, the emulsions used were not sensitive toward coalescence, and therefore, the effect of viscosity of the dispersed phase was minor.

Next, consider the wider implications of our work for understanding sensory fat perception. In the mouth, emulsions come into contact with a rough, hydrophobic and highly deformable surface, ${ }^{9}$ but also with saliva. Our results show that just like for emulsion lubrication, the presence of salivary proteins enhances the friction due to adherence of proteins to the surface. Interaction of saliva with an emulsion slightly lowers the friction, but still, the friction is higher than with emulsion alone. In a different set-up, Ranc et al. coated a pig's tongue with saliva,${ }^{30}$ dried the tongue and film and measured under these dry conditions the friction using a steel ball. In comparison to an uncoated dry tongue, the coated tongue gave rise to a lower friction. The lower friction in that case could be due to the presence of a sacrificial boundary layer, ${ }^{31}$ whereas in our case, saliva in its hydrated form can behave like a gel allowing boundary sliding between two interfacial salivary films similar to what is proposed by Hsu and Gates. ${ }^{31}$

Is influencing friction the only role saliva plays in inmouth lubrication? Saliva consists mainly of glycoprotein, mucins, which are highly surface-active and can form stable emulsions in the presence of oil. ${ }^{32}$ Experiments conducted with nonemulsified fat in the mouth show an extensively increased saliva production upon consumption (data not shown) in comparison to emulsified fat. After spitting out the nonemulsified oil, a stable emulsion is formed. This indicates that by producing saliva and thus exposing the free oil to the surface-active glyco-proteins, the hydrophobic tongue surface is cleaned very efficiently by creating an emulsion. The cleaning of the surface by saliva would also explain why high-weight fractions of oil do have an effect on in vivo sensory perception but not on in vitro friction experiments. High amounts of fat form a reservoir of lubricant counteracting the saliva cleaning-activity, and in that way, they prolong the 'fat' sensation.

Based on the present work, we can say that the mouth is boundary/mixed lubricated and thus that surface characteristics and interaction of the lubricant with the surface play 
an important role. Emulsions, which are sensitive toward surface-induced coalescence, containing a minimum amount of free protein, are most efficient in reducing inmouth friction (boundary/mixed) and thus in enhancing fat perception. There is no effect of emulsion fat content (in the range 1 to $40 \mathrm{wt} \%$ ) on friction. On the other hand, high amounts of oil do allow for the prolonged constant formation of such thin lubricating layers, and this may explain why the amount of fat is nevertheless important in fat perception.

Acknowledgement The authors thank Franklin Zoet and Jerry van Maanen of the WCFS for their valuable contribution in formulation of the emulsions, Marijke Beenes of B017 for managing the saliva donation, Marcel Bohmer of Philips Eindhoven for his help with the determination of the roughness and Prof. Nicolas Spencer and Seunghwan Lee of the ETHZ in Zurich for providing us with the method to modify the PDMS surfaces.

\section{References}

1. S. Giasson, J. Israelachvili and H. Yoshizawa, J Food Sci 62, 640 (1997).

2. S. Lee, M. Heuberger, P. Rousset, et al., Tribol Lett 16, 239 (2004).

3. G. Luengo, M. Tsuchiya, M. Heuberger, et al., J Food Sci 62, 767 (1997).

4. M.E. Malone, I.A.M. Appelqvist and I. T. Norton, Food Hydrocoll 17, 763 (2003).

5. R.A. Wijk de and J.F. Prinz, Food Qual Prefer 16, 121 (2005).

6. D.M. Dresselhuis, E.H.A. de Hoog, M.A. Cohen Stuart, et al., Food Hydrocoll doi:10.1016/j.foodhyd.2007.06.013 (2007).

7. A. Cambiella, J.M. Benito, C. Pazos, et al., Tribol Lett 22, 53 (2006).

8. S.P. Dubey, G.K. Sharma, K.S. Shishodia, et al., Industrial Lubrication and Tribology 57, 208 (2005).

9. D.M. Dresselhuis, E.H.A. de Hoog, M.A. Cohen Stuart, et al., Food Hydrocoll 22, 323 (2008).
10. F. Shama and P. Sherman, J. Texture Studies 4, 111 (1973).

11. J. de Vicente, H.A. Spikes and J.R. Stokes, Journal of TribologyTransactions of the Asme 128, 795 (2006).

12. C.E. Christersson, L. Lindh and T. Amebrant, Eur J Oral Sci 108, 418 (2000).

13. M.W.J. Dodds, D.A. Johnson and C.K. Yeh, J Dent 33, 223 (2005).

14. O. Svensson, L. Lindh, M. Cardenas, et al., J Colloid Interface Sci 299, 608 (2006).

15. S. Lee and N.D. Spencer, Tribol Int 38, 922 (2005).

16. E. Silletti, M.H. Vingerhoeds, W. Norde, et al., Food Hydrocoll 21, 596 (2007).

17. H. Stone and J.L. Sidel, Sensory evaluation practices (Orlando academic press 1985).

18. T.B.J. Blijdenstein, T. van Vliet, E. van der Linden, et al., Food Hydrocoll 17, 661 (2003).

19. M.P. Heuberger, M.R. Widmer, E. Zobeley, et al., Biomaterials 26, 1165 (2005).

20. G.D. Jay, D.A. Harris, and C.J. Cha, Glycoconj J 18, 807 (2001).

21. K.S.K. Karuppiah, S. Sundararajan, Z.H. Xu, et al., Tribol Lett 22, 181 (2006).

22. J.E. Pickard, J. Fisher, E. Ingham, et al., Biomaterials 19, 1807 (1998).

23. A.P. Serro, M.P. Gispert, M.C.L. Martins, et al., J Biomed Materi Res Part A 78A, 581 (2006).

24. M.R. Widmer, M. Heuberger, J. Voros, et al., Tribol Lett 10, 111 (2001).

25. J. Sibarani, M. Takai, and K. Ishihara, Colloids and Surfaces BBiointerfaces 54, 88 (2007).

26. E.H.A. de Hoog, J.F. Prinz, L. Huntjens, et al., J Food Sci 71, E337 (2006).

27. M.B. Frost, G. Dijksterhuis, and M. Martens, Food Qual Prefer 12, 327 (2001).

28. P.B. Moore, K. Langley, P.J. Wilde, et al., J Sci Food Agric 76, 469 (1998)

29. M.H. Vingerhoeds, R.A. de Wijk, F.D. Zoet, et al., Food Hydrocoll doi:10.1016/j.foodhyd.2007.02.011 (2007).

30. H. Ranc, C. Servais, P.F. Chauvy, et al., Tribol Int 39, 1518 (2006).

31. S.M. Hsu and R.S. Gates, Tribol Int 38, 305 (2005).

32. L. Shi, C. Miller, K.D. Caldwell, et al., Colloids and Surfaces BBiointerfaces 15, 303 (1999). 